\title{
Estimation of Circulating Drug Metabolite Exposure in Human Using In Vitro Data and Physiologically Based Pharmacokinetic Modeling: Example of a High Metabolite/Parent Drug Ratio ${ }^{\mathbb{S}}$
}

\author{
R. Scott Obach, Jian Lin, Emi Kimoto, Sridhar Duvvuri, Timothy Nicholas, Eugene P. Kadar, \\ Larry M. Tremaine, and Aarti Sawant-Basak
}

Department of Pharmacokinetics, Dynamics, and Drug Metabolism, Pfizer Inc., Groton, Connecticut (RSO, JL, EK, EPK, and RSO), and Cambridge, Massachusetts (ASB); and Department of Clinical Pharmacology, Pfizer Inc., Cambridge, Massachusetts $(S D$ and $T N)$

Received August 28, 2017; accepted November 14, 2017

\begin{abstract}
(R)-4-((4-((4-((tetrahydrofuran-3-yl)oxy)benzo[d]isoxazol-3-yl)oxy)methyl)piperidin-1-yl)methyl)tetrahydro-2H-pyran-4-ol (TBPT), a serotonin-4 receptor partial agonist, is metabolized to two metabolites: an $\mathbf{N}$-dealkylation product $[(\boldsymbol{R})$-3-(piperidin-4-ylmethoxy)-4((tetrahydrofuran-3-yl)oxy)benzo[d]isoxazole (M1)] and a cyclized oxazolidine structure [7-(((4-)((R)-tetrahydrofuran-3-yl)oxy)benzo [d]isoxazol-3-yl)oxy)methyl)octahydro-3H (M2)]. After administration of TBPT to humans the exposure to M1 was low and the exposure to M2 was high, relative to the parent drug, despite this being the opposite in vitro. In this study, projection of the plasma metabolite/parent (M/P) ratios for $M 1$ and $M 2$ was attempted using in vitro metabolism, binding, and permeability data in static and dynamic physiologically based pharmacokinetic (PBPK) models. In the static model, the fraction of parent clearance yielding the metabolite (which also required taking into account secondary
\end{abstract}

metabolites of M1 and M2), the clearance of the metabolites and parent, and an estimate of the availability of the metabolites from the liver were combined to yield estimated parent/metabolite ratios of 0.32 and $\mathbf{2 3}$ for M1 and M2, respectively. PBPK modeling that used in vitro and physicochemical data input yielded estimates of 0.26 and 20 , respectively. The actual values were 0.12 for M1/TBPT and 58 for M2/TBPT. Thus, the ratio for M1 was overpredicted, albeit at values less than unity. The ratio for M2/TBPT was underpredicted, and the high ratio of 58 may exceed a limiting ceiling of the approach. Nevertheless, when considered in the context of determining whether a potential circulating metabolite may be quantitatively important prior to administration of a drug for the first time to humans, the approaches succeeded in highlighting the importance of $\mathrm{M} 2$ (M/P ratio $>1$ ) relative to $\mathrm{M} 1$, despite $\mathrm{M} 1$ being much greater than $\mathrm{M} 2$ in vitro.

\section{Introduction}

Circulating drug metabolites have recently become a focus in the development of new drugs regarding safety and drug interactions (https://www.fda.gov/downloads/Drugs/GuidanceComplianceRegulatoryInformation/Guidances/UCM292340.pdf; http://www.ema. europa.eu/docs/en_GB/document_library/Scientific_guideline/2012/ 07/WC500129606.pdf; Yu et al., 2015). As new chemical entities to which humans can be exposed, the metabolites of drugs have the potential to exhibit various effects that may be either beneficial (pharmacological activity) or detrimental (toxicity). Despite this possibility, the frequency with which drug metabolites cause unwanted effects unrelated to the activity of the parent drug itself is very low (Smith and Obach, 2006; Isoherranen et al., 2009; Yu and Tweedie, 2013). Nevertheless, there are a few salient instances. For example, CYP2C8 inhibition caused by the

https://doi.org/10.1124/dmd.117.078279.

S This article has supplemental material available at dmd.aspetjournals.org. glucuronide metabolite of gemfibrozil was shown to be responsible for a serious drug interaction with cerivastatin (Shitara et al., 2004). Valvulopathy caused by dexfenfluramine could be attributed to the interaction of the nordexfenfluramine metabolite with the serotonin $2 \mathrm{~b}$ receptor (Rothman et al., 2000). Since human safety is at stake, the subject of drug metabolites merits attention, even if it is known that chemically stable circulating drug metabolites are rarely the culprit behind adverse drug effects.

Drug regulatory guidance on the issue of metabolites and safety has suggested that circulating metabolites comprising $10 \%$ or more of the total circulating drug-related material merit greater scrutiny with regard to safety (http://www.ich.org/fileadmin/Public_Web_Site/ICH_ Products/Guidelines/Multidisciplinary/M3_R2/Step4/M3_R2_Guideline. pdf). Such metabolites need to be present in laboratory animal species used in toxicology studies at abundances that approach or exceed the exposure observed in humans. Establishing that a metabolite comprises $10 \%$ or more of total drug-related material in circulation generally requires administration of radiolabeled drug to humans and quantitative radiometric profiling of plasma samples by high-pressure liquid

ABBREVIATIONS: ABT, 1-aminobenzotriazole; $\mathrm{AUC}$, area under the plasma concentration vs. time curve; $\mathrm{CL}$, clearance; $\mathrm{CL}_{\text {int }}$, intrinsic clearance; El, elasticity index; HBSS, Hanks' balanced salt solution; HLM, human liver microsomes; HPLC, high-performance liquid chromatography; M/P, metabolite/parent; MS, mass spectrometry; m/z, mass-to-charge ratio; M1, (R)-3-(piperidin-4-ylmethoxy)-4-((tetrahydrofuran-3-yl)oxy)benzo[d]isoxazole; M2, 7-(((4-(((R)-tetrahydrofuran-3-yl)oxy)benzo[d]isoxazol-3-yl)oxy)methyl)octahydro-3H,5H-spiro[oxazolo[3,2-a]pyridine-2,4'-pyran]; P450, cytochrome P450; PBPK, physiologically based pharmacokinetic; PK, pharmacokinetic; SCHH, sandwich-cultured human hepatocytes; SI, sensitivity index; SLE, supported liquid extraction; TBPT, (R)-4-((4-(((4-((tetrahydrofuran-3-yl)oxy)benzo[d]isoxazol-3-yl)oxy)methyl)piperidin-1yl)methyl)tetrahydro-2H-pyran-4-ol; $V_{s s}$, volume of distribution at steady state; UHPLC, ultrahigh pressure liquid chromatography. 
chromatography (HPLC). Such studies are frequently not done until well into a clinical development program, and if it is determined at this time that one or more metabolites in humans will require further analysis, this can hamper the progress of the development of the experimental drug. Therefore, a method whereby one could anticipate that a drug metabolite(s) will be major in human circulation prior to human studies of the drug would be valuable. Previous studies have shown that estimation of metabolite/parent (M/P) drug exposure ratios can be accomplished using in vitro data on the parent drug and metabolites (Lutz and Isoherranen, 2012; Nguyen et al., 2016a,b, 2017) in either a static model based on relationships first described by Houston (1981) or a dynamic physiologically based pharmacokinetic (PBPK) model. In the example drugs and metabolites used in those studies, the $\mathrm{M} / \mathrm{P}$ drug ratios in plasma were under seven. In an effort to test the limits of this approach, we have attempted to apply this approach to the experimental drug (R)-4-((4-(((4-((tetrahydrofuran-3-yl)oxy)benzo[d]isoxazol-3-yl)oxy)methyl)piperidin-1-yl)methyl)tetrahydro-2H-pyran-4-ol (TBPT), a partial agonist of the serotonin-4 receptor. In in vitro studies, it was shown that TBPT was metabolized by $N$-dealkylation to metabolite $(R)-3$ (piperidin-4-ylmethoxy)-4-((tetrahydrofuran-3-yl)oxy)benzo[d]isoxazole (M1) and a novel oxidative cyclization to an oxazolidine metabolite 7-(((4-(((R)-tetrahydrofuran-3-yl)oxy)benzo[d]isoxazol-3-yl)oxy)methyl)octahydro-3H (M2), among others (Fig. 1) (Sawant-Basak et al., 2013). The metabolite M1 was major in vitro, whereas M2 was minor; however, a preliminary evaluation of human plasma samples from healthy volunteers dosed with TBPT showed that M2 was in vast excess relative to M1 and TBPT (at least 20-fold) (Sawant-Basak et al., 2013). The objective of the studies reported herein is to test the aforementioned static and PBPK modeling approaches to determine whether they can reasonably project that a minor in vitro metabolite (M2) can be expected to have high relative abundance in plasma.

\section{Materials and Methods}

\section{Materials}

TBPT, M1, and M2 were prepared at Pfizer Inc., Groton, CT (Brodney et al., 2012; Sawant-Basak et al., 2013). Human hepatocytes for suspension incubations were a custom pool of 10 donors (seven female; three male) prepared by Bioreclamation (Westbury, NY), and cryopreserved hepatocyte lots HH1026 and HH1027 (both lots were prepared from the same female donor) used in the sandwich-cultured system were from In Vitro ADMET (Columbia, MD). Human liver and intestinal microsomes were from 50 and 10 donors, respectively (equal number of male and female donors) and were obtained from Corning-Gentest (Woburn, MA). In VitroGro-HT (thawing), InVitroGro-CP (plating), and

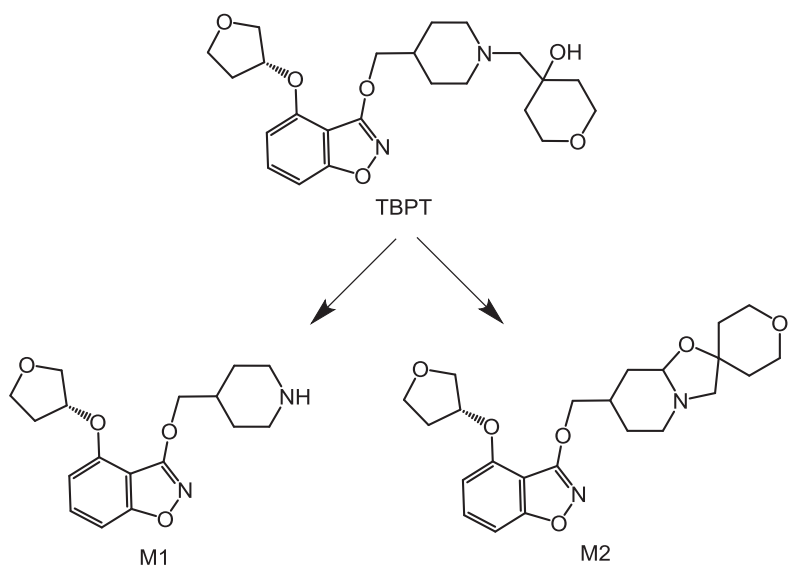

Fig. 1. Structures of TBPT, M1, and M2.
In VitroGro-HI (incubation) hepatocyte media were purchased from Bioreclamation/IVT (Baltimore, MD). Hanks' balanced salt solution (HBSS) was purchased from Lonza (Walkersville, MD). BioCoat 24-well plates and Matrigel were purchased from Corning (Bedford, MA). Pierce BCA Protein Assay Kit was purchased from Thermo Fisher Scientific (Waltham, MA).

\section{Metabolite Profile of TBPT, M1, and M2 in Human Hepatocytes}

TBPT, M1, or M2 $(10 \mu \mathrm{M})$ were incubated with pooled cryopreserved human hepatocytes $(750,000$ cells $/ \mathrm{ml})$ in $1.0 \mathrm{ml}$ Williams $\mathrm{E}$ medium in a humidified incubator maintained at $37^{\circ} \mathrm{C}, 75 \%$ relative humidity, and an atmosphere of $95 \%$ $\mathrm{O}_{2} / 5 \% \mathrm{CO}_{2}$. At $0,0.5$, and 3 hours an aliquot was removed $(0.3 \mathrm{ml})$ and added to $\mathrm{CH}_{3} \mathrm{CN}(1.2 \mathrm{ml})$. The precipitant was removed by centrifugation $(5$ minutes, $1700 \mathrm{~g}$ ), and then the supernatant was transferred to a clean tube and removed by vacuum centrifugation. The resulting residue was reconstituted in $0.06 \mathrm{ml} 1 \%$ formic acid. The reconstituted samples were injected $(0.01 \mathrm{ml})$ onto a Waters Acquity HSS T3 column $(2.1 \times 100 \mathrm{~mm} ; 1.7 \mu$ particle size $)$ equilibrated in $0.1 \%$ formic acid in $5 \% \mathrm{CH}_{3} \mathrm{CN}$ at a flow rate of $0.4 \mathrm{ml} / \mathrm{min}$. This mobile phase composition was held for 0.5 minutes followed by a linear gradient to $70 \%$ $\mathrm{CH}_{3} \mathrm{CN}$ at 4.5 minutes, $95 \% \mathrm{CH}_{3} \mathrm{CN}$ at 4.6 minutes, and held at this composition for 1 minute, followed by re-equilibration to initial conditions for 1.3 minutes. The eluent was introduced sequentially through a diode array detector (200-400 nm) and then into an ionspray source of a Thermo LTQ Orbitrap Mass Spectrometer (Thermo Fisher Scientific) operated in the positive ion mode. Various experiments were run in the mass spectrometer to gather fragmentation data in support of structural assignment of metabolites.

\section{Enzyme Kinetics of Formation of M1 and M2 from TBPT}

TBPT $(0.2-200 \mu \mathrm{M})$ was incubated with pooled human liver microsomes (HLM) $(1.0 \mathrm{mg} / \mathrm{ml})$ in $0.1 \mathrm{ml}$ potassium phosphate buffer $(100 \mathrm{mM}, \mathrm{pH} 7.45)$ containing $\mathrm{MgCl}_{2}(3.3 \mathrm{mM})$ and NADPH $(1.3 \mathrm{mM})$. Incubations, in triplicate, were started with the addition of NADPH and were carried out for 10 minutes at $37^{\circ} \mathrm{C}$. Incubations were stopped by the addition of $0.5 \mathrm{ml} \mathrm{CH}_{3} \mathrm{CN}$ containing $200 \mathrm{nM}$ clozapine (as an internal standard). The mixtures were spun in a centrifuge for 5 minutes at $1700 \mathrm{~g}$ and a portion of the supernatant $(0.4 \mathrm{ml})$ was removed by vacuum centrifugation. The residues were reconstituted in $0.1 \mathrm{ml} 1 \%$ formic acid for analysis by UHPLC mass spectrometry (MS). An identical set of incubations were done in pooled human intestinal microsomes, except that the microsomal protein concentration used was $2.0 \mathrm{mg} / \mathrm{ml}$.

The reconstituted samples were injected $(0.01 \mathrm{ml})$ onto a Waters Acquity HSS T3 column $(2.1 \times 100 \mathrm{~mm} ; 1.7 \mu$ particle size; Waters, Milford, MA) equilibrated in $1 \%$ formic acid in $5 \% \mathrm{CH}_{3} \mathrm{CN}$ at a flow rate of $0.4 \mathrm{ml} / \mathrm{min}$. This mobile phase composition program was the same as previously described. The eluent was introduced into an ionspray source of the Thermo LTQ Orbitrap Mass Spectrometer (Thermo Fisher Scientific) operated in the positive ion mode. The instrument was operated in the $\mathrm{MS}^{1}$ scanning mode [mass-to-charge ratio $(\mathrm{m} / \mathrm{z})$ 300-650] at a resolution of 30,000. Quantitation was done from reconstructed ion chromatograms of $m / z 319.1660$ (M1, $R_{\mathrm{t}}=3.58$ minutes), $\mathrm{m} / z 431.2183$ (M2; $R_{\mathrm{t}}=3.81$ minutes), and 327.1377 (clozapine internal standard, $R_{\mathrm{t}}=3.76$ minutes). The standard curve range was from 5.0 to $2000 \mathrm{nM}$. Enzyme kinetic data were derived from $V$ versus [S] data using GraphPad Prism v7.02 (GraphPad Software, Inc., La Jolla, CA).

\section{Metabolic Lability of TBPT, M1, and M2 in Human Liver and Intestinal Microsomes}

TBPT, M1, or M2 $(1.0 \mu \mathrm{M})$ were incubated with $\operatorname{HLM}(2.0 \mathrm{mg} / \mathrm{ml})$, in $1.0 \mathrm{ml}$ potassium phosphate buffer $(100 \mathrm{mM}, \mathrm{pH} 7.45)$ containing $\mathrm{MgCl}_{2}(3.3 \mathrm{mM})$ and NADPH $(1.3 \mathrm{mM})$. Incubations, in triplicate, were started with the addition of $\mathrm{NADPH}$ and were carried out at $37^{\circ} \mathrm{C}$. At $0,2,5,10,15,20,30$, and 45 minutes an aliquot $(0.1 \mathrm{ml})$ was removed and added to $0.5 \mathrm{ml} \mathrm{CH}_{3} \mathrm{CN}$ containing $200 \mathrm{nM}$ clozapine (as an internal standard). Samples were processed and analyzed as described previously. A similar experiment was done for TBPT in pooled human intestinal microsomes.

\section{Permeability and Transport of TBPT, M1, and M2 in Sandwich-Cultured Human Hepatocytes (SCHH)}

Plateable cryopreserved hepatocytes were thawed and plated as described previously (Kimoto et al., 2015). Briefly, hepatocytes were thawed in a water bath 
at $37^{\circ} \mathrm{C}$ and placed on ice. The cells were then poured into In VitroGro-HT medium (Bioreclamation/IVT) at $37^{\circ} \mathrm{C}$ at a ratio of one vial $/ 50 \mathrm{ml}$ in a conical tube. The cells were centrifuged at $50 \mathrm{~g}$ for 3 minutes and resuspended at $0.75 \times$ $10^{6}$ cells $/ \mathrm{ml}$ in In VitroGro-CP medium (Bioreclamation/IVT). Cell viability was determined by Trypan Blue exclusion and exceeded $85 \%$. On day 1 , hepatocyte suspensions were plated in collagen-coated 24-well plates at a density of $0.375 \times$ $10^{6}$ cells/well in a volume of $0.5 \mathrm{ml} /$ well. After $18-24$ hours of incubation at $37^{\circ} \mathrm{C}$, cells were overlaid with ice-cold $0.25 \mathrm{mg} / \mathrm{ml}$ Matrigel in In VitroGro-HI medium (Bioreclamation/IVT) at $0.5 \mathrm{ml} /$ well and cultured for 5 days.

On day 5, the hepatocytes were first rinsed twice with $\mathrm{Ca}^{2+} / \mathrm{Mg}^{2+}$ containing HBSS (standard) or $\mathrm{Ca}^{2+} / \mathrm{Mg}^{2+}$-free HBSS and then preincubated for 10 minutes with standard or $\mathrm{Ca}^{2+} / \mathrm{Mg}^{2+}$-free HBSS in the absence or presence of $1 \mathrm{mM}$ 1-aminobenzotriazole (ABT) or $1 \mathrm{mM} \mathrm{ABT/1} \mathrm{mM} \mathrm{rifamycin} \mathrm{SV.} \mathrm{After} \mathrm{aspirating}$ the preincubation buffer, $0.5 \mathrm{ml}$ of incubation buffer containing substrate $(1 \mu \mathrm{M})$ was added in the absence or presence of ABT/rifamycin SV. The uptake was terminated at designated times $(0.5,1,2,5,10$, and 20 minutes) by adding $0.5 \mathrm{ml}$ of ice-cold standard HBSS after removal of the incubation buffer. Cells were then washed three times with $0.5 \mathrm{ml}$ of ice-cold standard HBSS. The hepatocytes were lysed with methanol containing the internal standard for liquid chromatographyMS/MS quantification.

TBPT, M1, and M2 were analyzed on a Triple Quadrupole 6500 Mass Spectrometer (SCIEX, Framingham, MA) equipped with a TurboIonSpray interface connected to a SLC-30A LC system (Shimadzu, Kyoto, Japan) and HTC PAL Autosampler (LEAP Technologies, Carrboro, NC). Samples (10 $\mu \mathrm{l})$ were injected onto a Kinetex C18 column $(2.6 \mu, 100 \AA$, $30 \times 3.0 \mathrm{~mm}$; Phenomenex, Torrance, $\mathrm{CA}$ ) and eluted by mobile phase with initial conditions of $10 \%$ solvent B, followed by a linear gradient of $10 \%$ solvent B to $100 \%$ solvent B over 4 minutes at a flow rate of $0.4 \mathrm{ml} / \mathrm{min}$ (solvent A: $100 \%$ water with $0.1 \%$ formic acid; solvent $\mathrm{B}: 90 \% \mathrm{CH}_{3} \mathrm{CN} / 10 \%$ water with $0.1 \%$ formic acid). The mass transitions in positive ion mode for monitoring TBPT, M1, and M2 were $\mathrm{m} / \mathrm{z}$ $433 \rightarrow 194,319.1 \rightarrow 98$, and $431.2 \rightarrow 210$, respectively.

\section{Projection of Metabolite/Parent Drug Ratios by Static Modeling}

The following equation relates the M/P plasma area under the curve (AUC) ratio $\left(\mathrm{AUC}_{\mathrm{m}} / \mathrm{AUC}_{\mathrm{p}}\right)$ after oral administration of the parent (Nguyen et al., 2016a,b) derived from original equations described by Houston (1981):

$$
\frac{A U C_{m}}{A U C_{p}}=\frac{F_{m} \cdot f_{C L, m} \cdot C L_{p}}{F_{h} \cdot C L_{m}}+\frac{F_{m} \cdot F_{m, g u t} \cdot f_{g u t C L, m} \cdot\left(1-F_{g}\right) \cdot C L_{p}}{F_{g} \cdot F_{h} \cdot C L_{m}}
$$

The first term represents the ratio driven by liver and the second term represents the ratio driven by the gut during first pass. The latter is needed because the metabolites being investigated are generated by CYP3A4, which has a meaningful presence in the intestine. The blood clearance $(C L)$ values for hepatic $\mathrm{CL}_{\mathrm{p}}$ and $\mathrm{CL}_{\mathrm{m}}$ were generated by scaling the in vitro intrinsic $\mathrm{CL}\left(\mathrm{CL}_{\mathrm{int}}\right)$ values for parent and metabolite $\left(\mathrm{CL}_{\text {int,p }}\right.$ and $\left.\mathrm{CL}_{\text {int, } \mathrm{m}}\right)$ using factors of $45 \mathrm{mg}$ microsomal protein per gram liver and $20 \mathrm{~g}$ of liver per kilogram of body weight, and inserting these into the well-stirred model of hepatic clearance (Pang and Rowland, 1977):

$$
\begin{aligned}
C L_{p} & =\frac{Q_{h} \cdot f_{u, p} \cdot C L_{i n t, p}}{Q_{h}+f_{u, p} \cdot C L_{i n t, p}} \\
C L_{m} & =\frac{Q_{h} \cdot f_{u, m} \cdot C L_{i n t, m}}{Q_{h}+f_{u, m} \cdot C L_{i n t, m}}
\end{aligned}
$$

where a value of $21 \mathrm{ml} / \mathrm{min} / \mathrm{kg}$ was used for hepatic blood flow $\left(Q_{\mathrm{h}}\right)$, and $f_{\mathrm{u}, \mathrm{p}}$ and $f_{\mathrm{u}, \mathrm{m}}$ represent the free fractions in blood for parent and metabolite, respectively. The fraction of the parent that evades first pass hepatic extraction $\left(F_{\mathrm{h}}\right)$ was estimated as

$$
F_{h}=1-\frac{C L_{p}}{Q_{h}}
$$

The values for the fraction of clearance of parent drug proceeding through a metabolite in the liver $\left(f_{\mathrm{CL}, \mathrm{m}}\right)$ and gut $\left(f_{\text {gutCL,m }}\right)$ were estimated using two approaches. The first used the in vitro metabolite formation intrinsic clearance for each pathway directly (i.e., $V_{\max } / K_{\mathrm{M}}$ ) divided by the total in vitro intrinsic clearance of parent consumption determined by the in vitro half-life, $t_{1 / 2}\left(\mathrm{CL}_{\text {int }}=0.693 / \mathrm{in}\right.$ vitro $t_{1 / 2}$, corrected for the concentration of microsomes). This was calculated for liver and intestinal microsomes, separately as follows:

$$
f_{C L, m}=\frac{C L_{\text {int }, \text { metabolite formation }}}{C L_{\text {int }, \text { parent consumption }}}
$$

In the second approach, secondary metabolites arising from M1 and M2 were added to their respective formation $\mathrm{CL}_{\text {int }}$ values. The $\mathrm{UV}$ peak areas of M1, M2, and their secondary metabolites from the metabolite profile (as previously described) were determined (assuming similar molar extinction coefficients for the metabolites, which is reasonable since the benzisoxazole chromophore is unaltered). The peak area for M1 and its secondary metabolites $(\mathrm{m} / \mathrm{z} 335$ and 415$)$ (Fig. 2) were summed and the $\mathrm{M} \mathrm{CL}_{\text {int }}$ value was multiplied by the ratio of peak areas of this sum divided by the peak area of M1 itself. The same was done for M2 by including the peak area of the secondary metabolite $\mathrm{m} / \mathrm{z} 333$ (Fig. 2). This accounts for underestimates of $\mathrm{CL}_{\text {int }}$ due to any further metabolism of the metabolites that were missed in the enzyme kinetic experiments. Similar data sets were used previously in the estimation of $f_{\mathrm{m}}$ values for use in projecting $\mathrm{M} / \mathrm{P}$ ratios for imipramine and losartan (Nguyen et al., 2016a, 2017).

The values for $F_{\mathrm{m}}$ for metabolites, i.e. the fraction of the metabolite formed in the liver that escapes into the systemic circulation, were estimated from the following equation:

$$
F_{m}=\frac{Q_{h}}{Q_{h}+f_{u, m} \cdot C L_{i n t, m}}
$$

where the parameters are as previously described. The value for the parent availability through the gut following oral administration $\left(F_{\mathrm{g}}\right)$ was estimated as

$$
F_{g}=\frac{Q_{g u t}}{Q_{g u t}+f_{u, p} \cdot C L_{\text {int }, p, g u t}}
$$

where $Q_{\text {gut }}$ is the villous blood flow ( $4 \mathrm{ml} / \mathrm{min} / \mathrm{kg}$ ); $f_{\mathrm{u}, \mathrm{p}}$ is the unbound fraction of parent drug in blood; and $\mathrm{CL}_{\text {int,p.gut }}$ is the intrinsic clearance for parent consumption in the intestine scaled from intestinal microsomal lability. A value of $2978 \mathrm{mg}$ microsomes per intestine was used (Hatley et al., 2017). The corresponding value for $F_{\mathrm{m} \text {,gut }}$ was assumed to be unity. The M/P ratios were adjusted to accommodate differences in molecular weight between metabolites and parent drug.

\section{Dynamic Physiologically Based Pharmacokinetic Modeling in Simcyp}

The PBPK models for TBPT and its two metabolites, M1 and M2, were developed to simulate the observed disposition profile of the metabolites after daily oral administration of TBPT (15 mg P.O.) using the population-based PBPK simulator Simcyp (version 15; Simcyp Ltd., Sheffield, United Kingdom). The simulations were performed for a virtual population of 100 healthy volunteers $(10$ trials $\times 10$ subjects each $)$ aged between 20 and 50 years with a male/female ratio of 50/50. For TBPT, a full PBPK model was developed assuming perfusion-limited distribution and using physicochemical properties $\left(\mathrm{p} K_{\mathrm{a}}, \log \mathrm{P}\right)$, biochemical properties (human plasma $f_{\mathrm{u}}$, blood-toplasma ratio), and in vitro metabolic $\mathrm{CL}_{\mathrm{int}}$ values. The absorption model was first order, with an absorption rate constant set at $0.6 \mathrm{~h}^{-1}$ based on clinical data. The $F_{\mathrm{a}}$ value was set at 0.6 based on in vitro permeability assay and preclinical PK parameters.

For $\mathrm{M} 1$ and $\mathrm{M} 2$, the volume of distribution at steady state $\left(V_{\mathrm{ss}}\right)$ was predicted using method 1 within the Simcyp simulator (Simcyp Ltd.), which is based on input parameters of protein binding and lipophilicity. The $V_{\mathrm{ss}}$ values of M1 and $\mathrm{M} 2$ were predicted to be 1.64 and $0.26 \mathrm{l} / \mathrm{kg}$, respectively. The $V_{\mathrm{ss}}$ value for TBPT was estimated by allometric scaling of $\operatorname{dog} V_{\mathrm{ss}}$ data. The $\mathrm{M} 1$ and $\mathrm{M} 2 \mathrm{CL}_{\text {int }}$ values were obtained from in vitro metabolic stability of each of the two analytes in HLM. Enzyme kinetic information using HLM was selected for TBPT metabolism.

Sensitivity analysis was performed to identify which parameters must be known with the greatest accuracy to most accurately predict the $\mathrm{AUC}_{\mathrm{m}}$ values of TBPT metabolites. The parameters investigated included TBPT, M1, and M2 formation intrinsic clearance, elimination intrinsic clearance, plasma protein binding, blood-to-plasma ratio, and $\log \mathrm{P}$. The metrics examined were the AUC and $C_{\max }$ values of M1 and M2 after oral administration of TBPT at $15 \mathrm{mg}$. 


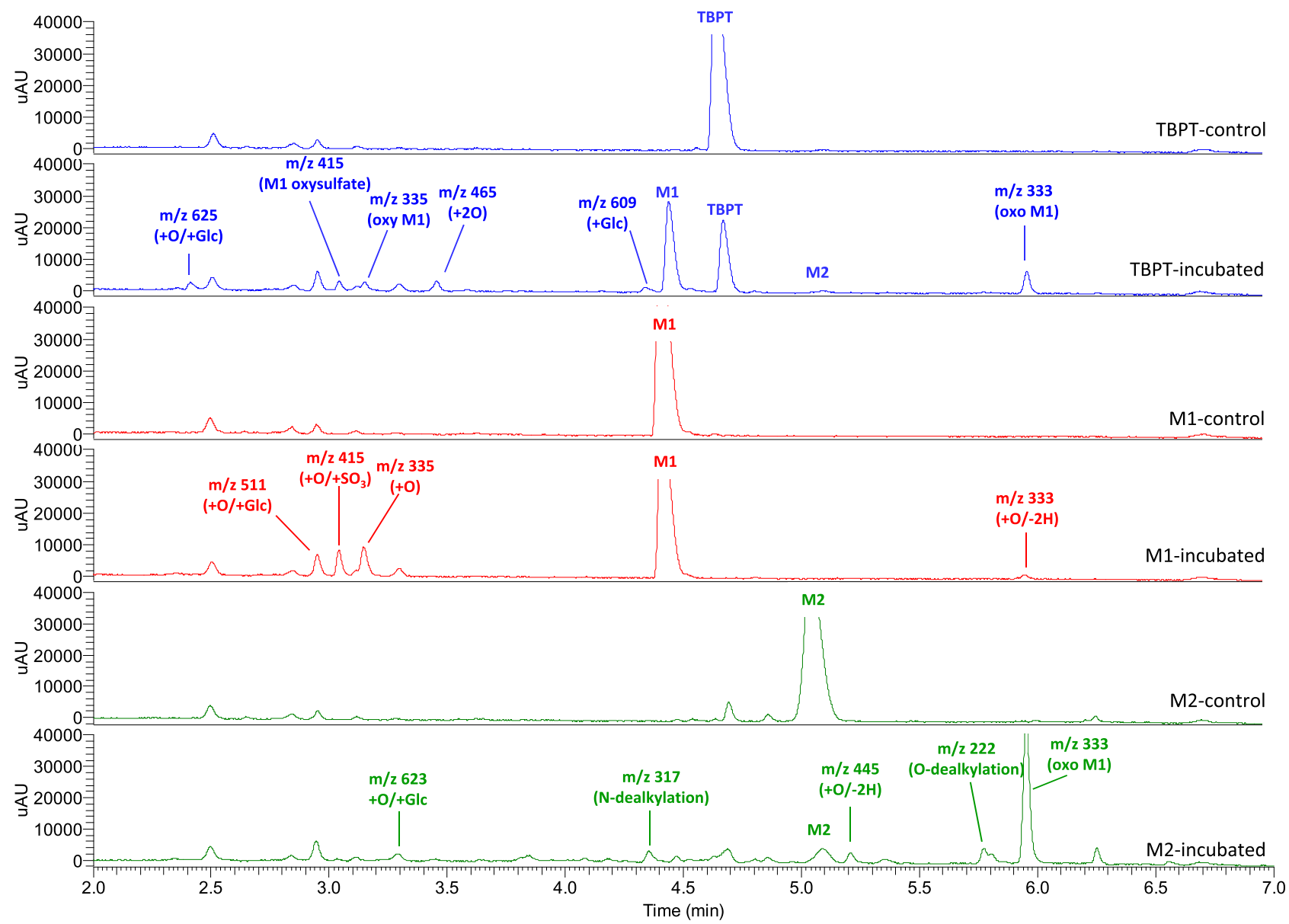

Fig. 2. HPLC-UV traces of extracts of hepatocyte incubations of TBPT, M1, and M2.

The sensitivity of the M1 and M2 AUC and $C_{\max }$ values to $0.1 \%$ changes in the mean values of selected parameters using Simcyp version 15 (Simcyp Ltd.) was calculated. The elasticity index (EI) is a dimensionless expression of sensitivity [i.e., the sensitivity index (SI)] that measures the relative change in an output variable $Q$ (e.g., AUC) for a relative change in an input parameter $P$. The EI was calculated as follows for each input parameter value $n$ :

$$
\mathrm{EI}_{\mathrm{n}}=\left(\frac{P_{n}}{Q\left(P_{n}\right)}\right) \cdot \mathrm{SI}
$$

where $Q\left(P_{n}\right)$ is the value of $Q$ when $P=P_{n}$ and SI is a measure of the change in the output variable $Q$ per unit change in the input parameter value $P_{n+1}$ from its initial value $P_{n}$, calculated using the following equation:

$$
\mathrm{SI}_{n}=\frac{Q\left(P_{n+1}\right)-Q\left(P_{n}\right)}{P_{n+1}-P_{n}}
$$

The EIs were used to rank the importance of parameters on the output variables.

\section{Clinical Pharmacokinetics}

This clinical study was conducted in compliance with the ethical principles originating in or derived from the Declaration of Helsinki and in compliance with all International Conference on Harmonization Good Clinical Practice Guidelines and the International Ethical Guidelines for Biomedical Research Involving Human Subjects (Council for International Organizations of Medical Sciences 2002). In addition, all local regulatory requirements were fulfilled, particularly those affording greater protection to the safety of study participants.

Dosing of Human Volunteers and Collection of Samples. The clinical pharmacokinetic $(\mathrm{PK})$ data were available from a phase 1 multiple-dose escalation study in healthy adult and elderly subjects (Nicholas et al., 2011). From this study, the present analysis was done for just the healthy subject data from the $15 \mathrm{mg} / \mathrm{day}$ group on days 1 and 14 . The demographic characteristics for this group $(N=8$; four Caucasian and four African-American subjects) were as follows: age, 31.6 years (range 21-49); weight, $83.9 \mathrm{~kg}$ (range 67.1-99.8); and body mass index, 27.6 (range 24.2-29.7). Predose samples were also collected on days $1,2,3,4,5,6,7,8,10,12$, and 14 to assess if steady state was reached in the study.

Assay of TBPT and Metabolites. The HPLC-MS/MS method was validated for the analysis of TBPT, M1, and M2 in human plasma treated with $\mathrm{K}_{2}$ EDTA anticoagulant. Internal standard $\left(0.05 \mathrm{ml}\right.$ of $1.60 \mathrm{ng} / \mathrm{ml}$ in $\left.\mathrm{H}_{2} \mathrm{O} / \mathrm{CH}_{3} \mathrm{CN}\right)$ was added to the samples followed by extraction utilizing methyl-tert butyl etherbased supported liquid extraction (SLE) [isolute SLE + SLE plate $(400 \mu \mathrm{l})$; Biotage, Charlotte, NC]. The SLE extracts were evaporated under nitrogen at $35^{\circ} \mathrm{C}$. The reconstituted extracts were injected $(15 \mu \mathrm{l})$ onto a liquid chromatographic system consisting of a Shimadzu solvent delivery system (LC-20AD), Shimadzu autosampler (Prominence SIL-20AC refrigerated to $8^{\circ} \mathrm{C}$ ), Shimadzu column oven (CTO-20AC) operated at $30^{\circ} \mathrm{C}$, and a SCIEX API 5000 tandem mass spectrometer. The chromatographic separation was achieved using a Phenomenex Luna C18(2), $50 \times 2.0 \mathrm{~mm}, 5 \mu \mathrm{m}$ analytical column equipped with an Upchurch $0.5 \mu \mathrm{m}$ prefilter (IDEX Corp., Middleborough, MA). The following gradient was applied utilizing $0.1 \%$ formic acid in water and $0.1 \%$ formic acid in methanol as mobile phase A and mobile phase B (respectively: $0.01-2.00$ minutes (25\%-60\% B); 2.00-2.20 (60\%-95\% B); $2.20-3.00$ (hold at 95\% B); 3.00-3.35 (95\%-25\% B); 3.35-4.00 (hold at 25\% B); 4.00-5.50 (25\%$65 \%$ B); $5.50-5.60$ (hold at $65 \%$ B); $5.60-5.80(65 \%-25 \%$ B); and 5.80-6.50 (hold at $25 \% \mathrm{~B}$ ). Eluent from the liquid chromatography was analyzed by a SCIEX API 5000 tandem mass spectrometer operated in positive electrospray mode. The following transitions were monitored: TBPT $(433.3 \rightarrow 212.2)$; M1 $(319.3 \rightarrow 98.1)$; M2 (431.3 $\rightarrow$ 210.2); $\left[{ }^{2} \mathrm{H}_{9}\right]$ TBPT (internal standard $\left.1,442.3 \rightarrow 221.2\right)$; and $\left[{ }^{2} \mathrm{H}_{9}\right]$ 

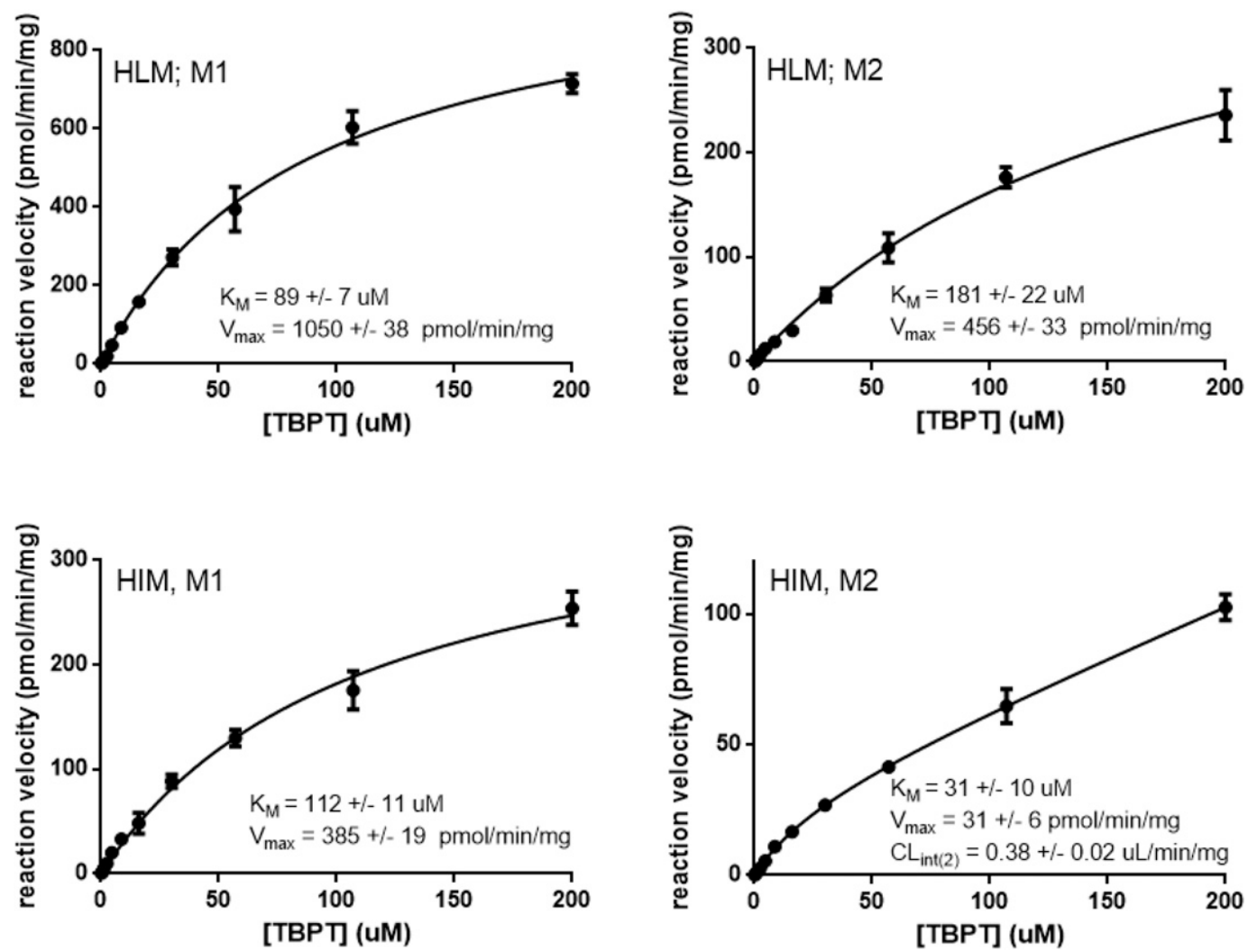

Fig. 3. Enzyme kinetic plots for the formation of metabolites M1 and M2 from TBPT in human liver and intestine microsomes.

M1 (internal standard 2, 328.3 $\rightarrow$ 107.1). The approximate retention times were as follows: TBPT (1.12 minutes); M1 (1.06 minutes); M2 (1.42 minutes); $\left[{ }^{2} \mathrm{H}_{9}\right] \mathrm{TBPT}$ (1.11 minutes); and $\left.{ }^{2} \mathrm{H}_{9}\right] \mathrm{M} 1$ (1.05 minutes). The dynamic range of the assay was $5.00-7500 \mathrm{pg} / \mathrm{ml}$ for TPBT, $2.00-3000 \mathrm{pg} / \mathrm{ml}$ for M1, and $25.0-37500 \mathrm{pg} / \mathrm{ml}$ for M2. A linear $\left(1 / x^{2}\right)$ regression was applied to the analyte/internal standard peak area ratios utilizing Applied Biosystems/MDS SCIEX Analyst (version 1.5, Concord, Ontario, Canada) and Watson (version 7.3.0.01).

Pharmacokinetic Calculations. Standard PK parameters, $C_{\max }$ (maximum plasma concentration), $T_{\max }$ (time for $C_{\max }$ ), and $\mathrm{AUC}_{\tau}$ (area under the plasma concentration vs. time curve over the dosing interval) were calculated using noncompartmental analyses. The PK calculations were done using an internal program called eNCA that uses S-PLUS scripts to calculate noncompartmental parameters. The PK data from healthy adults at $15 \mathrm{mg}$ daily dose on days 1 and 14 are presented for comparison against model predictions.

\section{Results}

Metabolite Profiles of TBPT, M1, and M2 in Human Hepatocytes. In order to know what in vitro systems would offer good quantitative representations of clearance (i.e., the types of initial metabolic reactions that TBPT, M1, and M2 undergo) must be known. Hepatocytes were selected as a suitable in vitro system since they possess a nearly complete array of drug metabolizing enzymes and cofactors. HPLC-UV profiles of extracts of hepatocyte incubations of TBPT, M1, and M2 are shown in Fig. 2. For TBPT, the vast majority of metabolism is via oxidative routes with the exception of a very small amount of direct glucuronidation. (A proposed metabolism scheme for TBPT, M1, and M2 is shown in Supplemental Fig. 1). Observation of a large peak for M1 as well as a few downstream metabolites suggests that $N$-dealkylation is the major route of TBPT metabolic clearance. For the metabolism of M1, all initial metabolic reactions are oxidative, with some subsequent conjugation. For M2, metabolism was extensive and all initial pathways also appeared to be via oxidative biotransformation. Thus, in subsequent intrinsic clearance measurements, liver microsomes with cofactors and conditions in support of cytochrome P450 (P450) activity were used for all three compounds, since initial metabolic clearance pathways were all via $\mathrm{P} 450$ oxidation reactions. It is important to note that the major metabolite of M2 is denoted as oxo-M1 $(\mathrm{m} / \mathrm{z}, 333)$ (see Supplemental Fig. 1) and that this metabolite was also observed in the incubation of TBPT but very slightly in the incubation of M1 itself. From M2, this would arise via $N$-dealkylation of the piperidine iminium ion tautomer of M2 (i.e., metabolite designated as $m / z, 317$ eluting at a retention time of 4.35 minutes in Fig. 2), followed by oxidation of the imine to the lactam. Thus, inclusion of oxo-M1 as an important contribution to the M2 pathway is important in estimating the formation $\mathrm{CL}_{\text {int }}$ for $\mathrm{M} 2$ (as discussed subsequently).

TABLE 1

Enzyme kinetic parameters for the metabolism of TBPT, M1, and M2 in human liver and intestinal microsomes

\begin{tabular}{lccc}
\hline & $V_{\max }$ & $\mathrm{K}_{\mathrm{M}}$ & $\mathrm{CL}_{\text {int }}$ \\
\hline & $p$ mol/min/mg & $\mu M$ & $\mu l / m i n / m g$ \\
Liver microsomes & & & \\
TBPT $\rightarrow$ M1 & $1050 \pm 38$ & $89 \pm 7$ & 12 \\
TBPT $\rightarrow$ M2 & $456 \pm 33$ & $181 \pm 22$ & 2.5 \\
TBPT consumption & - & - & 32 \\
M1 consumption & - & - & 32 \\
M2 consumption & - & - & 102 \\
Intestinal microsomes & & $112 \pm 11$ & 3.4 \\
TBPT $\rightarrow$ M1 & $385 \pm 19$ & $31 \pm 6$ & $1.4^{a}$ \\
TBPT $\rightarrow$ M2 & $31 \pm 6$ & - & 13 \\
TBPT consumption & - & &
\end{tabular}

${ }^{a}$ Includes additional high $K_{\mathrm{M}}$ and high $V_{\max }$ activity. 

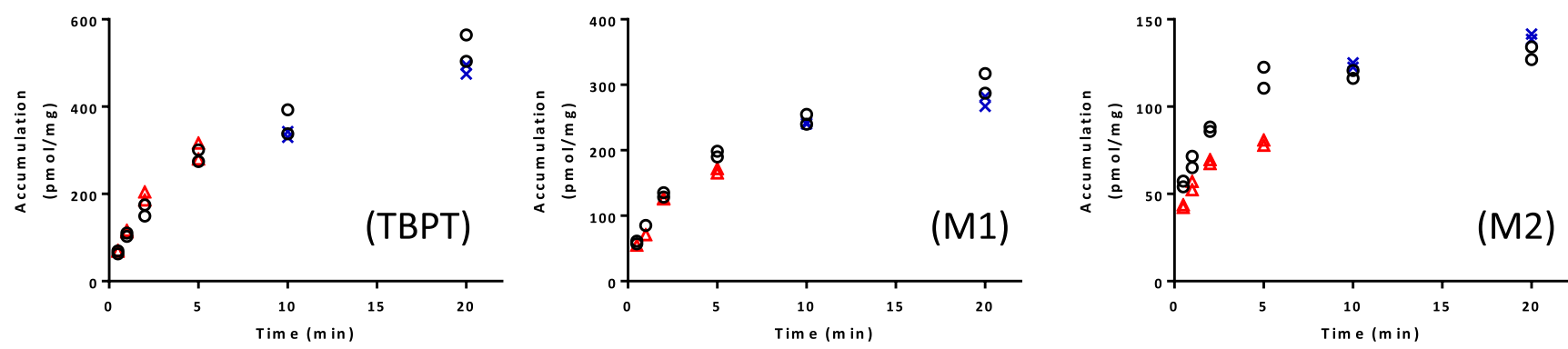

Fig. 4. Hepatic transport of TBPT, M1, and M2 in SCHH. The accumulation of TBPT, M1, and M2 was investigated at $37^{\circ} \mathrm{C}$ with standard $\mathrm{HBSS}$ (control) in the absence or presence of $1 \mathrm{mM}$ rifamycin SV/1 mM ABT or $\mathrm{Ca}^{2+} / \mathrm{Mg}^{2+}$-free HBSS in hepatocyte lot HH1027 for TBPT and HH1026 for M1 and M2. Black open circle (O) represents

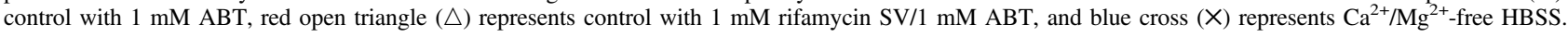

Enzyme Kinetics and Intrinsic Clearance of TBPT, M1, and M2. Enzyme kinetics of the conversion of TBPT to M1 and M2, as well as measurement of consumption of TBPT, M1, and M2 were all needed to make estimates of the $\mathrm{CL}_{\text {int }}$ and $f_{\mathrm{CL}, \mathrm{m}}$ values. These measurements were made in liver and intestinal microsomes. Substrate saturation plots for the formation of M1 and M2 from TBPT in liver and intestinal microsomes are shown in Fig. 3. For M1, the kinetics appeared to follow simple hyperbolic Michaelis-Menten kinetics with $K_{\mathrm{M}}$ values of 89 and $112 \mu \mathrm{M}$ in liver and intestine, respectively. The $\mathrm{CL}_{\text {int }}$ values were calculated to be 12 and $3.4 \mu \mathrm{l} / \mathrm{min} / \mathrm{mg}$ protein. For M2, the $K_{\mathrm{M}}$ values were 181 and $31 \mu \mathrm{M}$ in liver and intestine, respectively, and the $\mathrm{CL}_{\text {int }}$ values were 2.5 and $1.4 \mu \mathrm{l} / \mathrm{min} / \mathrm{mg}$ protein in liver and intestinal microsomes, respectively. The kinetic model best describing the formation of M2 in intestinal microsomes was a two-enzyme model with a high $K_{\mathrm{M}}$ activity that could only be described as a composite slope. The kinetic parameters are listed in Table 1.

Consumption of TBPT, M1, and M2 was also measured in liver microsomes. The $\mathrm{CL}_{\text {int }}$ values were estimated at 32,32 , and $102 \mu 1 / \mathrm{min} / \mathrm{mg}$ for TBPT, M1, and M2, respectively. Combining the formation kinetic data for M1 and M2 given previously with these total $\mathrm{CL}_{\text {int }}$ values for TBPT yielded estimates of the $f_{\mathrm{CL}, \mathrm{m}}$ values of 0.38 for $\mathrm{M} 1$ and 0.08 for $\mathrm{M} 2$ in liver. The total $\mathrm{CL}_{\text {int }}$ value for TBPT in intestinal microsomes was $13 \mu \mathrm{l} /$ $\mathrm{min} / \mathrm{mg}$, and combining this value with the formation $\mathrm{CL}_{\text {int }}$ values for M1 and $\mathrm{M} 2$ yielded estimates of $f_{\text {gutCL,m }}$ of 0.26 and 0.11 , respectively.

The estimates of formation $\mathrm{CL}_{\mathrm{int}}$ values for $\mathrm{M} 1$ and $\mathrm{M} 2$ were also corrected for the potential underestimation due to sequential metabolism. In these examples, such a correction was important since the consumption $\mathrm{CL}_{\text {int }}$ values for M1 and M2 exceeded their $\mathrm{CL}_{\text {int }}$ values for formation. For M1, this offered an incremental increase by a factor of 1.1-fold (based on the relative peak areas of secondary M1 metabolites to the peak area for M1). However, for M2 such an analysis was important since the $\mathrm{M} 2$ consumption $\mathrm{CL}_{\text {int }}$ value was substantially greater than its formation $\mathrm{CL}_{\text {int }}$ value (102 vs. $2.5 \mu \mathrm{l} / \mathrm{min} / \mathrm{mg}$ ) and the peak area for the secondary metabolite $\mathrm{m} / \mathrm{z}, 333$ was much larger than that for M2 itself in the HPLC trace of the metabolism of TBPT (Fig. 2). The $\mathrm{CL}_{\text {int }}$ value of formation for M2 was increased by a factor of 5.2. The fractions of the clearance value estimated in this manner were 0.41 and 0.41 for M1 and M2, respectively.

Hepatic Transport Study of TBPT, M1, and M2 in SCHH. The hepatic uptake of TBPT, M1, and M2 was investigated in human hepatocytes with an in vitro SCHH model. The accumulation of compounds in SCHH with standard HBSS with $1 \mathrm{mM} \mathrm{ABT}$, which is a pan $\mathrm{P} 450$ inhibitor, or with $1 \mathrm{mM} \mathrm{ABT/1} \mathrm{mM} \mathrm{rifamycin} \mathrm{SV}$, which is an OATP pan inhibitor, indicated passive diffusion or total uptake, respectively. The difference in compound accumulation in $\mathrm{SCHH}$ between standard HBSS and $\mathrm{Ca}^{2+} / \mathrm{Mg}^{2+}$-free HBSS represents a contribution of biliary excretion. As shown in Fig. 4, the uptake of
TBPT and M1 was not inhibited by rifamycin SV, whereas the uptake of M2 was slightly affected by rifamycin SV. The contribution of biliary excretion for all three was not determined under the test condition in the $\mathrm{SCHH}$ system. The in vitro $\mathrm{CL}_{\text {int }}$ values for total and passive transport are listed in Table 2.

Clinical Pharmacokinetic Data for TBPT, M1, and M2 Following Daily Oral Administration of TBPT. All of the subjects completed the study and were evaluated for adverse events, safety laboratory tests, and pharmacokinetics (Nicholas et al., 2011). There were no serious adverse events associated with this study. There were no vital signs, electrocardiogram, or safety laboratory test findings of potential clinical concern. Overall, TBPT was well tolerated up to a dose of $15 \mathrm{mg} /$ day over 14 days of dosing; the results from the $15 \mathrm{mg} /$ day dose in healthy adults are reported subsequently.

The mean plasma concentration versus time data are plotted in Fig. 5, and the mean PK parameters are listed in Table 3. TBPT demonstrated rapid absorption, with a median $T_{\max }$ occurring at 1-2 hours post dose. Following attainment of $C_{\max }$, plasma concentrations declined in a biphasic fashion and the average $\mathrm{CL}_{\mathrm{p}} / F$ ranged from 12 to $22 \mathrm{ml} / \mathrm{min} / \mathrm{kg}$ (correcting for a mean body weight of $83.9 \mathrm{~kg}$ ) across a dose range of $0.1-15 \mathrm{mg}$ daily in healthy adults. With repeated daily administration, plasma concentrations of TBPT were at steady state on day 14 and did not accumulate (as observed by median trough concentration vs. time profiles; data not shown).

The PK profiles of M1 and M2 following multiple daily dosing of $15 \mathrm{mg}$ TBPT are summarized in Fig. 5 and Table 3. Following oral dosing of $15 \mathrm{mg}$ daily TBPT, the mean $C_{\max }$ and $\mathrm{AUC}_{\tau}$ values of the $\mathrm{N}$-dealkylated metabolite M1 on day 1 were $1.7 \mathrm{ng} / \mathrm{ml}$ and $10.0 \mathrm{ng} \cdot \mathrm{h} / \mathrm{ml}$, respectively, which were $\sim 14$ - and $\sim 12$-fold lower than that of the parent, respectively, and there was no observable accumulation with repeated administration of TBPT. The overall ratio of M1:TBPT based

TABLE 2

In vitro intrinsic clearance values of TBPT, M1, and M2 in SCHH

The accumulation of TBPT, M1, and M2 $(1 \mu \mathrm{M})$ was investigated at $37^{\circ} \mathrm{C}$ with standard HBSS in the absence or presence of $1 \mathrm{mM}$ rifamycin SV/1 mM ABT or $\mathrm{Ca}^{2+} / \mathrm{Mg}^{2+}$-free HBSS in $\mathrm{SCHH}$. The in vitro CL values were calculated by initial rate analysis with a linear fitting up to 2 minutes. $\mathrm{CL}_{\text {uptake }}, \mathrm{CL}_{\text {passive }}$, and $\mathrm{CL}_{\text {bile }}$ represent the in vitro total uptake clearance, passive clearance, and biliary clearance when incubating with standard HBSS with $1 \mathrm{mM} \mathrm{ABT}$, standard HBSS with $1 \mathrm{mM}$ rifamycin SV/1 mM ABT, and $\mathrm{Ca}^{2+} / \mathrm{Mg}^{2+}$-free HBSS, respectively. Values in parentheses are S.E.

\begin{tabular}{lccc}
\hline Clearance & TBPT & M1 & M2 \\
\hline$\mu l / m i n / m g$ & & & \\
$\mathrm{CL}_{\text {uptake }}$ & $63(6.3)$ & $48(0.86)$ & $21(1.7)$ \\
$\mathrm{CL}_{\text {passive }}$ & $83(2.5)$ & $49(5.5)$ & $16(2.4)$ \\
$\mathrm{CL}_{\text {bile }}$ & $\mathrm{ND}$ & $\mathrm{ND}$ & $\mathrm{ND}$ \\
\hline
\end{tabular}

$\mathrm{ND}$, not determined. 

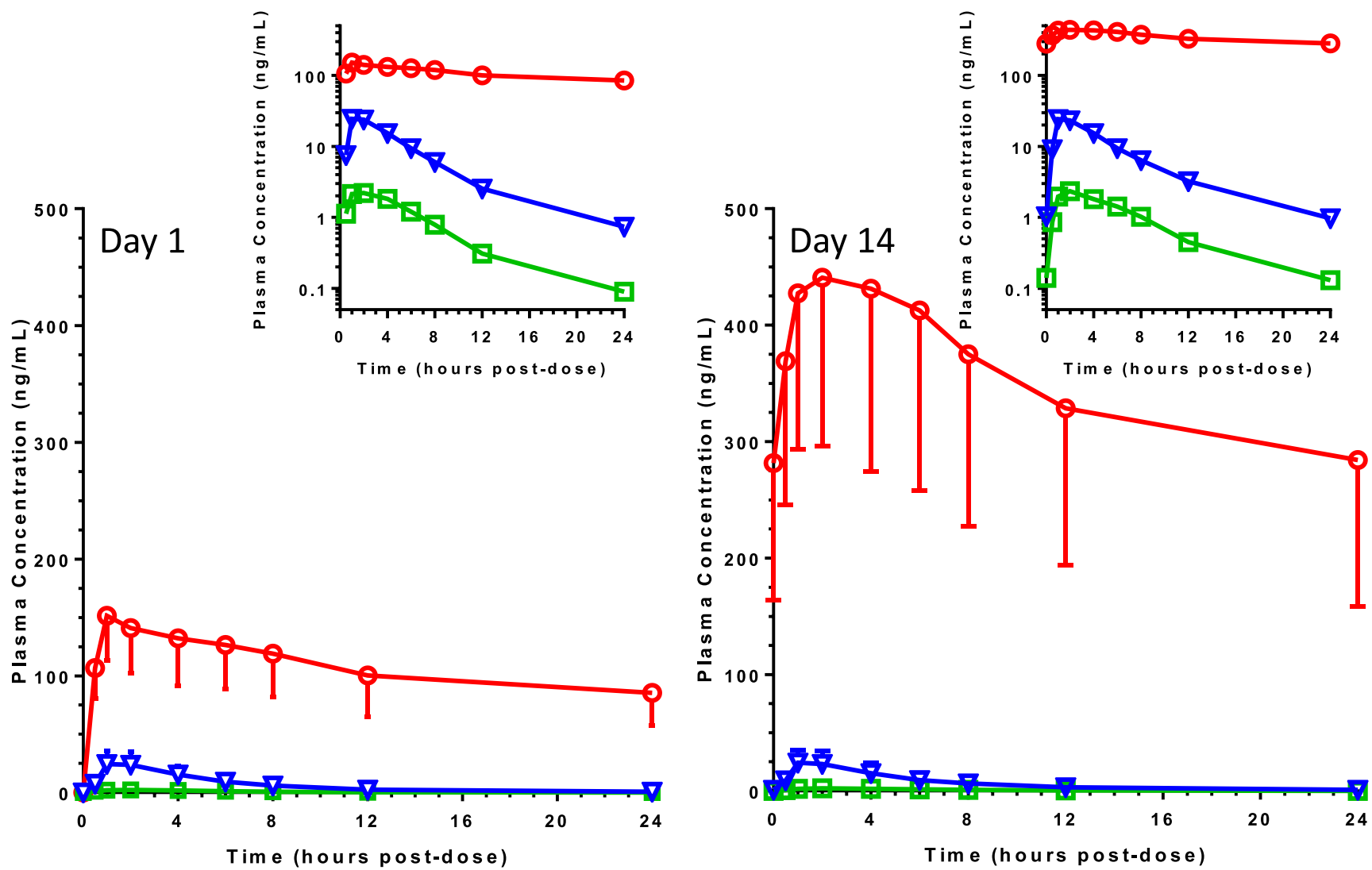

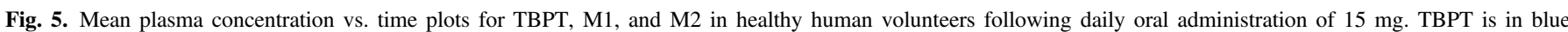
triangles, M1 in green squares, and M2 in red circles. Inset plots are the same data on a semilogarithmic scale.

on the $\mathrm{AUC}_{0-\tau}$ value was $0.08-0.09$ (0.11-0.12 when computed on a molar basis). In contrast, administration of TBPT led to high total plasma levels of M2 as assessed by the mean $C_{\max }$ and $\mathrm{AUC}_{\tau}$ values on days 1 and 14. At $15 \mathrm{mg}$ daily dose of TBPT the day 14 M2:TBPT exposure ratios were at least 2 - to 3 -fold greater than that on day 1 . The half-life of M2 could not be estimated due to insufficient regression points in the elimination phase. Comparing the concentration versus time profiles for M2 and TBPT it can be observed that M2 has a prolonged elimination rate, which was greater than that of the parent. This suggests elimination rate-limited kinetics.

Projection of Metabolite/Parent Exposure Ratios from Static Modeling. The measured values from the in vitro experiments were scaled to reflect the in vivo parameters and were used to calculate the terms needed in eq. 1 (Table 4). TBPT was projected to be a moderate clearance compound $\left(\mathrm{CL}_{\mathrm{p}}=7.9 \mathrm{ml} / \mathrm{min} / \mathrm{kg}\right.$, approximately $40 \%$ of hepatic blood flow), and while metabolite M1 was also projected to have moderate clearance $(11 \mathrm{ml} / \mathrm{min} / \mathrm{kg})$, the clearance for M2 was projected to be low $(0.4 \mathrm{ml} / \mathrm{min} / \mathrm{kg})$. This is despite the fact that the hepatic total intrinsic clearance of M2 is greater than that for TBPT or M1 and this low scaled clearance value is driven by the substantially greater plasma protein binding of M2. The percentages of metabolic clearance of TBPT proceeding through the pathways that yield M1 and M2 were $38 \%-41 \%$ for $\mathrm{M} 1$ and $8 \%-41 \%$ for M2. These were estimated by dividing the formation $\mathrm{CL}_{\text {int }}$ values for each metabolite by the total substrate

TABLE 3

Exposure metrics for TBPT, M1, and M2 in healthy human volunteers following daily oral administration of $15 \mathrm{mg}$ TBPT compared with values predicted using dynamic PBPK modeling

\begin{tabular}{|c|c|c|c|c|c|c|c|c|}
\hline \multirow{2}{*}{ Metric } & \multicolumn{2}{|c|}{ TBPT } & \multicolumn{3}{|c|}{ M1 } & \multicolumn{3}{|c|}{ M2 } \\
\hline & Predicted & Observed & Predicted $^{a}$ & Predicted $^{b}$ & Observed & Predicted & Predicted $^{b}$ & Observed \\
\hline \multicolumn{9}{|l|}{ Day 1} \\
\hline$C_{\max }(\mathrm{ng} / \mathrm{ml})^{c}$ & 32.6 & $23.1(45)$ & 5.2 & 5.4 & $1.7(77)$ & 36 & 182 & $148(28)$ \\
\hline$T_{\max }(\mathrm{h})^{d}$ & 2.9 & $1.5(1-2)$ & 3.4 & 3.5 & $1.5(1-2)$ & 8.9 & 8.9 & $1(0.5-2)$ \\
\hline $\mathrm{AUC}_{0-\tau}(\mathrm{ng} \cdot \mathrm{h} / \mathrm{ml})^{c}$ & 312 & $123(51)$ & 56 & 59 & $10.0(99)$ & 700 & 3541 & $2440(35)$ \\
\hline \multicolumn{9}{|l|}{ Day 14} \\
\hline$C_{\max }(\mathrm{ng} / \mathrm{ml})^{c}$ & 33.5 & $23.1(46)$ & 5.4 & 5.6 & $1.7(87)$ & 65 & 331 & $429(33)$ \\
\hline$T_{\max }(\mathrm{h})^{d}$ & 2.9 & $1(1-2)$ & 3.4 & 3.4 & $2(1-2)$ & 6.4 & 6.4 & $2(1-4)$ \\
\hline $\operatorname{AUC}_{0-\tau}(\mathrm{ng} \cdot \mathrm{h} / \mathrm{ml})^{c}$ & 322 & $134(55)$ & 58 & 62 & $11.6(102)$ & 1312 & 6723 & $7850(39)$ \\
\hline
\end{tabular}

$T_{\max }$, time to reach $C_{\max }$.

${ }^{a}$ Predicted using experimentally measured formation $\mathrm{CL}_{\mathrm{int}}$ values.

${ }^{b}$ Predicted using formation $\mathrm{CL}_{\text {int }}$ values corrected for secondary metabolism. All predicted values are point estimates of mean values.

${ }^{c}$ Values are mean $(\% \mathrm{CV})$ for AUC and $C_{\max }$.

${ }^{d}$ Values are median (range) for $T_{\max }$. 
TABLE 4

Estimated input parameters for static model prediction of $\mathrm{M} / \mathrm{P}$ drug ratios

The constants are $\mathrm{Q}_{\mathrm{h}}=21 \mathrm{ml} / \mathrm{min} / \mathrm{kg}, \mathrm{Q}_{\mathrm{gut}}=4 \mathrm{ml} / \mathrm{min} / \mathrm{kg} ; 45 \mathrm{mg}$ microsomes $/ \mathrm{gm}$ liver, $20 \mathrm{gm} \mathrm{liver} / \mathrm{kg} / \mathrm{b} . \mathrm{wt}$., and $2978 \mathrm{mg}$ microsomes whole intestine (i.e., $42 \mathrm{mg}$ intestinal microsomes $/ \mathrm{kg} / \mathrm{b}$.wt.).

\begin{tabular}{|c|c|c|}
\hline Parameter & Input Values & Scaled Value \\
\hline \multicolumn{3}{|l|}{ TBPT } \\
\hline $\mathrm{CL}_{\mathrm{p}}$ & $f_{\mathrm{u}}=0.38 ; \mathrm{B} / \mathrm{P}=0.86 ; \mathrm{CL}_{\mathrm{int}}=32 \mu \mathrm{l} / \mathrm{min} / \mathrm{mg}$ & $7.9 \mathrm{ml} / \mathrm{min} / \mathrm{kg}$ \\
\hline$F_{\mathrm{h}}$ & $\mathrm{CL}_{\mathrm{p}}=7.9 \mathrm{ml} / \mathrm{min} / \mathrm{kg}$ & 0.62 \\
\hline$F_{\mathrm{g}}$ & $f_{\mathrm{u}}=0.38 ; \mathrm{B} / \mathrm{P}=0.86 ; \mathrm{CL}_{\mathrm{int}}=13 \mu \mathrm{l} / \mathrm{min} / \mathrm{mg}$ & 0.94 \\
\hline \multicolumn{3}{|c|}{ Metabolite M1 } \\
\hline $\mathrm{CL}_{\mathrm{m}}$ & $f_{\mathrm{u}}=0.64 ; \mathrm{B} / \mathrm{P}=0.88 ; \mathrm{CL}_{\mathrm{int}}=32 \mu \mathrm{l} / \mathrm{min} / \mathrm{mg}$ & $11 \mathrm{ml} / \mathrm{min} / \mathrm{kg}$ \\
\hline$f_{\mathrm{CL}, \mathrm{m}}$ & $\mathrm{CL}_{\mathrm{int}, \mathrm{TBPT}}=32 \mu \mathrm{l} / \mathrm{min} / \mathrm{mg} ; \mathrm{CL}_{\mathrm{int}, \mathrm{TBPT} \rightarrow \mathrm{M} 1}=12 \mu \mathrm{l} / \mathrm{min} / \mathrm{mg}$ & 0.38 or $0.41^{a}$ \\
\hline$F_{\mathrm{m}}$ & $f_{\mathrm{u}}=0.64 ; \mathrm{B} / \mathrm{P}=0.88 ; \mathrm{CL}_{\mathrm{int}}=32 \mu \mathrm{l} / \mathrm{min} / \mathrm{mg}$ & 0.47 \\
\hline$f_{\text {gutCL,m }}$ & $\mathrm{CL}_{\mathrm{int}, \mathrm{TBPT}}=13 \mu \mathrm{l} / \mathrm{min} / \mathrm{mg} ; \mathrm{CL}_{\mathrm{int}, \mathrm{TBPT}} \rightarrow \mathrm{M} 1=3.4 \mu \mathrm{l} / \mathrm{min} / \mathrm{mg}$ & 0.26 or $0.30^{a}$ \\
\hline$F_{\text {m,gut }}$ & Assumed as unity & 1 \\
\hline \multicolumn{3}{|c|}{ Metabolite M2 } \\
\hline $\mathrm{CL}_{\mathrm{m}}$ & $f_{\mathrm{u}}=0.0025 ; \mathrm{B} / \mathrm{P}=0.53 ; \mathrm{CL}_{\mathrm{int}}=102 \mu \mathrm{l} / \mathrm{min} / \mathrm{mg}$ & $0.40 \mathrm{ml} / \mathrm{min} / \mathrm{kg}$ \\
\hline$f_{\mathrm{CL}, \mathrm{m}}$ & $\mathrm{CL}_{\text {int }, \mathrm{TBPT}}=32 \mu \mathrm{l} / \mathrm{min} / \mathrm{mg} ; \mathrm{CL}_{\mathrm{int}, \mathrm{TBPT}} \rightarrow \mathrm{M} 2=2.5 \mu \mathrm{l} / \mathrm{min} / \mathrm{mg}$ & 0.08 or $0.41^{a}$ \\
\hline$F_{\mathrm{m}}$ & $f_{\mathrm{u}}=0.0025 ; \mathrm{B} / \mathrm{P}=0.53 ; \mathrm{CL}_{\text {int }}=102 \mu \mathrm{l} / \mathrm{min} / \mathrm{mg}$ & 0.98 \\
\hline$f_{\text {gutCL,m }}$ & $\mathrm{CL}_{\text {int }, \mathrm{TBPT}}=13 \mu \mathrm{l} / \mathrm{min} / \mathrm{mg} ; \mathrm{CL}_{\text {int }, \mathrm{TBPT}} \rightarrow \mathrm{M} 2=1.4 \mu \mathrm{l} / \mathrm{min} / \mathrm{mg}$ & 0.11 or $0.58^{a}$ \\
\hline$F_{\text {m,gut }}$ & Assumed as unity & 1 \\
\hline
\end{tabular}

$\mathrm{B} / \mathrm{P}$, blood-to-plasma ratio.

${ }^{a}$ Values are corrected for by secondary metabolism (see Materials and Methods).

consumption intrinsic clearance of TBPT. The higher percentages include the correction for secondary metabolism. The fractions of each metabolite generated within the liver that evades further immediate metabolism were estimated from the projected $\mathrm{CL}_{\text {int }}$ values of the metabolites versus liver blood flow. For M2, it was estimated that almost all metabolites leave the liver prior to further hepatic clearance, whereas for M1 about half of the metabolites generated undergo subsequent clearance prior to release from the liver. Putting all of these factors together in the static model, eq. 1 yielded that the projected M/P exposure ratios for M1 and M2 were 0.29 and 4.2, respectively, using the measured formation $\mathrm{CL}_{\text {int }}$ values only, and were 0.32 and 23, respectively, following correction of the formation $\mathrm{CL}_{\text {int }}$ values for unmeasured secondary metabolism (Table 7). For M2, its rapid metabolism to secondary metabolites had a large impact on the projection of the M/P ratio, whereas for M1 this factor did not have much impact. Finally, because most of TBPT is projected to evade first pass intestinal metabolism $\left(F_{\mathrm{g}}=0.94\right)$ little of the exposure to metabolites M1 and M2 is due to their generation in the intestine; almost all of the exposure derives from the liver.

Projection of Metabolite/Parent Exposure Ratios from Dynamic PBPK Modeling. The input parameters used for PBPK modeling are summarized in Table 5. The predicted versus observed plasma

TABLE 5

Simcyp input parameters for TBPT, M1, and M2

\begin{tabular}{|c|c|c|c|c|}
\hline Parameter & TBPT & M1 & M2 & Source \\
\hline Molecular weight (g/mol) & 432 & 318 & 430 & Calculated $^{e}$ \\
\hline $\log \mathrm{P}$ & 1.68 & 2.19 & 2.08 & Calculated $^{e}$ \\
\hline Compound type & Monoprotic base & Monoprotic base & Monoprotic base & \\
\hline $\mathrm{p} K_{\mathrm{a}}$ & 8.8 & 10.22 & 6.48 & Calculated $^{e}$ \\
\hline $\mathrm{B} / \mathrm{P}$ & 0.86 & 0.88 & $0.55^{a}$ & Measured \\
\hline$f_{\mathrm{u}, \mathrm{p}}$ & 0.38 & 0.64 & 0.0025 & Measured \\
\hline \multicolumn{5}{|l|}{ Absorption } \\
\hline Model & First order & NA & NA & \\
\hline Fraction absorbed & 1 & NA & NA & Assumed \\
\hline$k_{\mathrm{a}}(1 / \mathrm{h})$ & 0.6 & NA & NA & Fitting \\
\hline$f_{\mathrm{u}}(\mathrm{gut})$ & 1 & 1 & 1 & Assumed \\
\hline $\begin{array}{l}\text { Manin-Darby Canine Kidney } \\
\text { Cell Permeability }\left(10^{-6} \mathrm{~cm} / \mathrm{s}\right)\end{array}$ & 23 & NA & NA & Measured \\
\hline \multicolumn{5}{|l|}{ Distribution } \\
\hline Model & Minimal PBPK & Minimal PBPK & Minimal PBPK & \\
\hline$V_{\text {ss }}(1 / \mathrm{kg})$ & $2.1^{b}$ & $1.64^{c}$ & $0.26^{c}$ & Fitting \\
\hline \multicolumn{5}{|l|}{ Elimination } \\
\hline $3 \mathrm{~A} 4 \mathrm{CL}_{\text {int }}(\mu \mathrm{l} / \mathrm{min} / \mathrm{mg})$ (forming M1) & 12 or $13^{d}$ & & & Measured \\
\hline $3 \mathrm{~A} 4 \mathrm{CL}_{\mathrm{int}}(\mu \mathrm{l} / \mathrm{min} / \mathrm{mg})$ (forming $\mathrm{M} 2$ ) & 2.5 or $13^{d}$ & & & Measured \\
\hline Additional HLM CL $\mathrm{L}_{\text {int }}(\mu \mathrm{l} / \mathrm{min} / \mathrm{mg})$ & 17.5 or 6 & 32 & 102 & Measured \\
\hline
\end{tabular}

B/P, blood-to-plasma ratio.

${ }^{a}$ Minimum value for Simcyp is 0.55 ; measured value was 0.53 .

${ }^{b}$ Predicted using dog PK data.

${ }^{c}$ Value from Simcyp using method 1.

${ }^{d} \mathrm{CL}_{\text {int }}$ values represent measured values and measured values multiplied by factors of 1.1 and 5.2 for $\mathrm{M} 1$ and $\mathrm{M} 2$, respectively, to account for secondary metabolism.

${ }^{e}$ Calculated using ACD/Labs Software (Advanced Chemistry Software, Toronto, Ontario, Canada) 

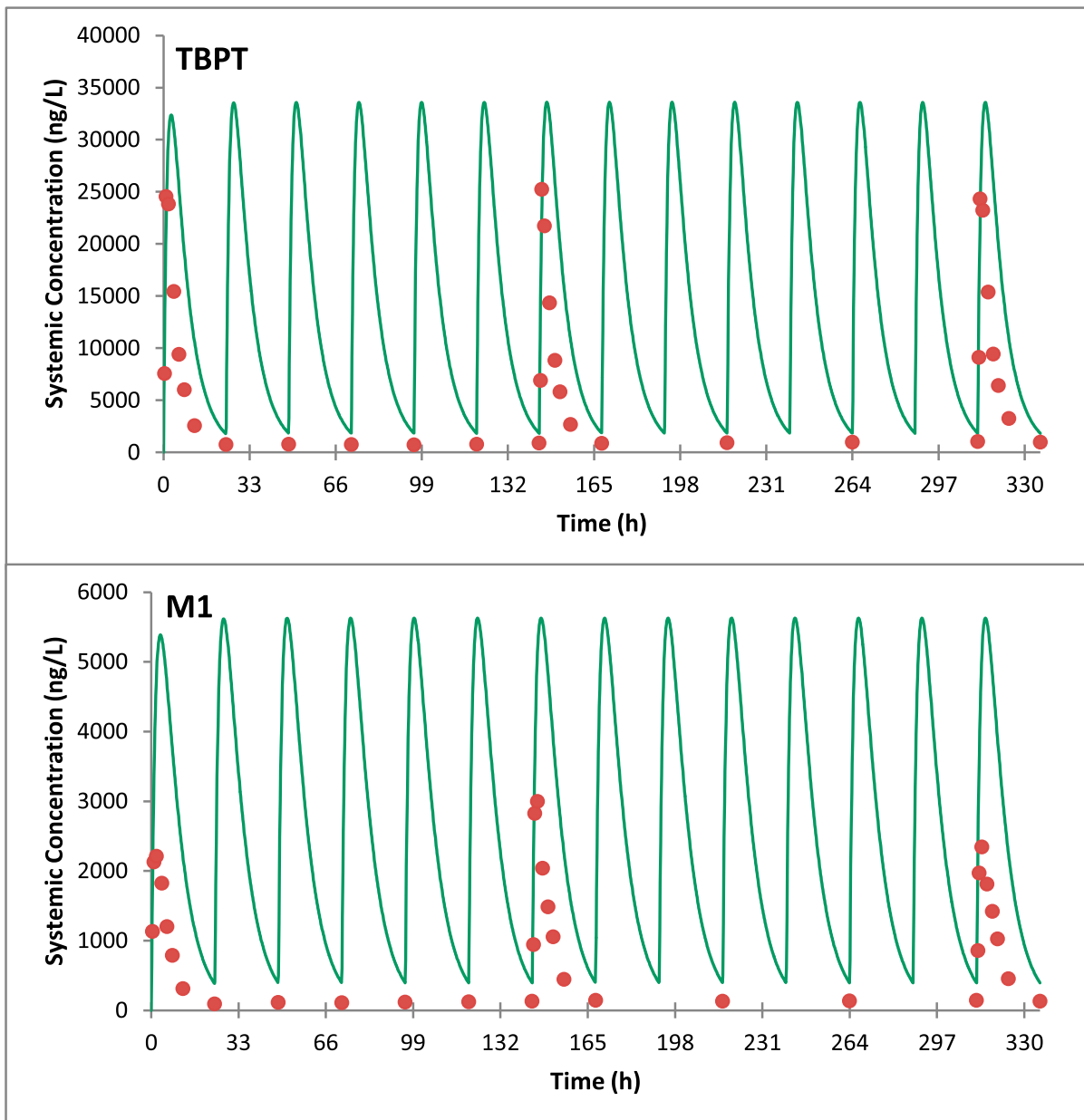

Fig. 6. Comparison of plasma concentration vs. time profiles for TBPT, M1, and M2 simulated by PBPK modeling vs. actual clinical data. Red circles represent the mean measured concentrations and green lines represent the simulated profiles.

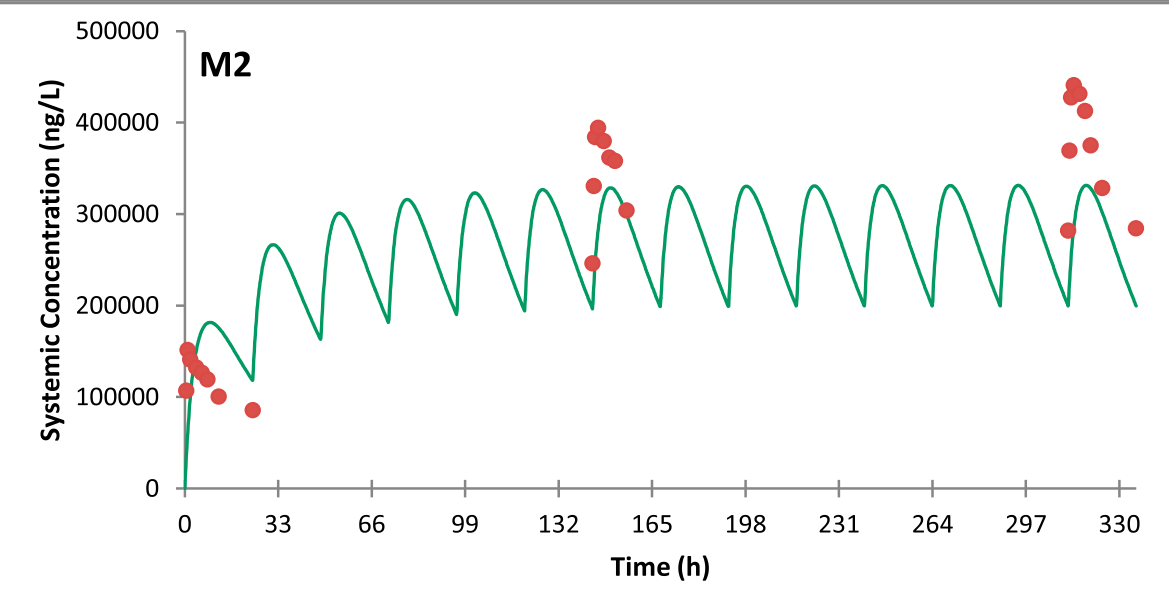

concentration-time profiles of TBPT, M1, and M2 following oral administration of TBPT $(15 \mathrm{mg})$ are displayed in Fig. 6. The predicted PK parameters are summarized and tabulated in Table 3 for comparison with the measured parameters. Overall, PBPK modeling can reasonably recover the oral profiles of TBPT and its metabolites using in vitro metabolic input parameters. After oral dosing of $15 \mathrm{mg}$ the predicted mean $\mathrm{AUC}_{0-\tau}$ value for TBPT was $312 \mathrm{ng} \cdot \mathrm{h} / \mathrm{ml}$, which was 2.5 -fold higher than the observed mean value of $123 \mathrm{ng} \cdot \mathrm{h} / \mathrm{ml}$, while the mean $C_{\max }$ value was overpredicted by 1.4 -fold $(32.6 \mathrm{vs}$. $23.1 \mathrm{ng} / \mathrm{ml})$. The predicted $\mathrm{AUC}_{0-\tau}$ value of $\mathrm{M} 1$ was $56 \mathrm{ng} \cdot \mathrm{h} / \mathrm{ml}$, which was 5.6 -fold higher than the observed value of $10 \mathrm{ng} \cdot \mathrm{h} / \mathrm{ml}$. Thus, for both parent drug and M1, the exposure was somewhat overpredicted; however, the M/P ratio for M1 was better predicted since the overpredictions of exposure were partially off-setting (the predicted ratio was 0.24 while the actual ratio was 0.12 ). Accumulation upon repeated administration was neither predicted nor observed.

However, for $\mathrm{M} 2$ on day 1 the observed $\mathrm{AUC}_{0-\tau}$ value was $2440 \mathrm{ng} \cdot \mathrm{h} / \mathrm{ml}$, whereas the predicted value was only $700 \mathrm{ng} \cdot \mathrm{h} / \mathrm{ml}$. Accumulation of 1.9-fold was predicted for M2 while the actual accumulation was 3.2 , thus the underprediction of the $\mathrm{M} / \mathrm{P}$ ratio was greater for multiple dosing, wherein the observed $\mathrm{AUC}_{0-\tau}$ value was $7850 \mathrm{ng} \cdot \mathrm{h} / \mathrm{ml}$ while the projected value was $1312 \mathrm{ng} \cdot \mathrm{h} / \mathrm{ml}$. However, 
as was the case for the static model, taking into account the experimental underestimation of the metabolite formation $\mathrm{CL}_{\mathrm{int}}$ value for $\mathrm{M} 2$ altered the estimation of metabolite exposures in dynamic PBPK modeling and substantially improved these. The predicted $\mathrm{AUC}_{0-\tau}$ value increased to 3541 and $6723 \mathrm{ng} \cdot \mathrm{h} / \mathrm{ml}$ for days 1 and 14, respectively. The day 1 model projection was an $\sim 1.5$-fold overestimate while the day 14 projection was fairly accurate ( $86 \%$ of the actual value). The $\mathrm{M} / \mathrm{P}$ ratio at steady state was estimated at 20 compared with the actual value of 58 , and this was largely driven by the overestimate of parent exposure.

The sensitivity analysis of the main PBPK model input parameters revealed that the values for plasma protein binding and intrinsic clearance for the metabolite are the two most sensitive parameters for estimates of M1 and M2 AUC values (Table 6). Clearance of formation of the metabolites was also sensitive for M2 and a bit less so for M1. The $\log \mathrm{P}$ and blood/plasma ratios were much less sensitive parameters.

\section{Discussion}

In the development of new drug candidates, possessing an ability to predict major metabolites in human circulation prior to administration in phase 1 clinical trials would be of benefit. Such predictions could be used in identifying/predicting important circulating drug-related material and in making decisions regarding which putative metabolites to synthesize and analyze in plasma samples from preclinical toxicology studies and first-in-human studies. The pharmacokinetic principles underlying the exposure to metabolites have existed for decades (Houston, 1981; St-Pierre et al., 1988) and contributing factors include the fraction of the clearance of the parent drug that proceeds via conversion to the metabolite of interest $\left(f_{\mathrm{m}}\right)$, the relative systemic clearance rates for the metabolite and parent $\left(\mathrm{CL}_{\text {parent }}\right.$, and $\left.\mathrm{CL}_{\text {metabolite }}\right)$, and the fraction of the metabolite that enters the systemic circulation from its organ of generation (most typically the liver) prior to it being further cleared $\left(F_{\mathrm{m}}\right)$. These parameters can be used in static models and they also underlie the algorithms used in more complex PBPK models. Several in vitro experiments can be done to generate data used to estimate these input values. Despite these principles being decades old, examples of their practical application have only been recently described. Lutz and Isoherranen (2012) carried out work wherein the exposures to metabolites of omeprazole and dextromethorphan were estimated using these principles. Likewise, work from Nguyen et al. (2016a,b, 2017) applied both static and PBPK modeling to estimate plasma exposures to metabolites of midazolam, imipramine, and losartan. Such methods are challenged by the many different mechanisms of metabolite generation and clearance and how well these can be measured using in vitro approaches. Furthermore, despite the complexity of the equations and models, several assumptions regarding parent drug and metabolite disposition are necessary to simplify the approach to this challenge.

TBPT offered a unique opportunity to test these approaches because there were two metabolites measured in clinical studies, wherein one

\section{TABLE 6}

Normalized sensitivity coefficients (elasticity indices) for selected parameters of M1 and M2 PBPK models

\begin{tabular}{lllllll}
\hline & \multicolumn{2}{c}{ M1 } & & \multicolumn{2}{c}{ M2 } \\
\cline { 2 - 3 } \cline { 5 - 6 } & $C_{\max }$ & AUC & & $C_{\max }$ & AUC \\
\hline Plasma protein binding $\left(f_{\mathrm{u}}\right)$ & 1.053 & 1.03 & & 0.863 & 0.972 \\
Blood-to-plasma ratio $(\mathrm{B} / \mathrm{P})$ & 0.176 & 0.0003 & & 0.801 & 0.007 \\
Log P & 1.097 & 0.002 & & 0.412 & 0.214 \\
$\mathrm{CL}_{\text {int }}$ (metabolite formation) & 0.731 & 0.592 & & 0.603 & 0.595 \\
$\mathrm{CL}_{\text {int }}$ (metabolism of metabolite) & 0.773 & & 0.997 & & 0.807 & 0.912 \\
\hline
\end{tabular}

was in great excess relative to the parent drug (M2) and the other was present at far lower concentrations than the parent drug (M1), while the opposite was observed in in vitro metabolism studies using humanderived reagents (Sawant-Basak et al., 2013). Metabolite M2 was considered unimportant from in vitro profiles and exemplifies the shortcomings of attempting to relate in vitro metabolite profile data directly to human plasma metabolite profiles without other considerations (Dalvie et al., 2009; Loi et al., 2013). The projection of the M/P exposure ratio for $\mathrm{M} 1$ was in reasonable agreement with the actual data (0.12 actual vs. $0.26-0.32$ predicted, see Table 7 ). While just over 2-fold inaccurate, when taken from a perspective of drug development, correct decisions would be made regarding the lack of need to analyze and better understand this metabolite, and despite M1 being a major clearance pathway observed in vitro its exposure in vivo is low, which is likely due to subsequent systemic metabolic clearance that is faster than that of the parent drug.

The M/P AUC ratio for M2 was underestimated (Fig. 6; Table 7). Based on the in vitro data, M2 was formed via oxidation in human liver, with very little in the intestine based on the estimated $F_{\mathrm{g}}$ value of 0.94 for TBPT. M2 was marked by a rapid rise in human plasma ( $T_{\max }$ of 1 hour post dose of TBPT), followed by a biphasic elimination profile where the slope of its elimination from plasma was estimated to be lower than that of TBPT, suggesting elimination rate-limited kinetics. This phenomenon could partly explain why the exposure to M2 was higher than anticipated; the day 14 plasma profile shows that it accumulated with repeat administration of TBPT, which could again be attributed to the low clearance and prolonged plasma elimination half-life. This elimination rate-limited kinetic profile is in contrast to the high total intrinsic clearance of M2 (102 $\mu \mathrm{l} / \mathrm{min} / \mathrm{mg})$ due to its rapid turnover in human hepatocytes; scaled clearance using binding parameters and intrinsic clearance in the well-stirred model predicted a $\mathrm{CL}_{\mathrm{m}}$ value of $0.4 \mathrm{ml} / \mathrm{min} /$ $\mathrm{kg}$ for M2, which was more than 10-fold lower than that for TBPT $(7.9 \mathrm{ml} / \mathrm{min} / \mathrm{kg}$ ). Accumulation of M2 on day 14 can be accounted for by the elimination half-life and would be independent of the half-life of the parent.

In vivo clearance values for TBPT and M2 are not available since neither has been directly administered intravenously. However, it is likely that the total clearance of M2 is lower than for TBPT, which would be due to the very high plasma protein binding of M2 relative to TBPT (150-fold higher). The in vitro intrinsic clearance of M2 is substantially more rapid than its formation intrinsic clearance. This disparity can lead to an underestimate of formation $\mathrm{CL}_{\text {int }}$, even though enzyme kinetic measurements were made using conditions wherein linear rates of formation are observed experimentally. Failure to take this into account yields a large underestimate of the M2/TBPT ratio. The observation of the secondary metabolite of M2 (labeled as $m / z, 333$ in Fig. 2) as an important metabolite in incubations starting with TBPT (present at 5-fold greater apparent abundance than M2 itself) suggests that the measured $\mathrm{M} 2$ formation $\mathrm{CL}_{\text {int }}$ value of $2.5 \mu \mathrm{l} / \mathrm{min} / \mathrm{mg}$ was underestimated. Inclusion of this factor in the prediction of the M2/TBPT ratio

TABLE 7

Overall comparisons of predicted and actual M/P ratios for M1 and M2 in plasma following administration of TBPT

\begin{tabular}{llllc}
\hline & M1/TBPT Ratio & \multicolumn{2}{c}{ M2/TBPT Ratio } \\
\hline Measured steady-state value & \multicolumn{2}{c}{$0.12^{a}$} & \multicolumn{2}{c}{$58^{a}$} \\
$f_{\text {CL,m value used in modeling }}$ & 0.38 & 0.41 & 0.08 & 0.41 \\
Static model prediction & 0.29 & 0.32 & 4.2 & 23 \\
Simcyp model prediction (single dose) & 0.24 & 0.24 & 2.2 & 11 \\
Simcyp model prediction (multiple dose) & 0.24 & 0.26 & 4.1 & 20 \\
\hline
\end{tabular}

${ }^{a}$ Ratios of mean AUC values. 
was important and increased estimates of 4.1-4.2 to estimates of 20-23 in PBPK and static models, respectively. While the latter estimates are still smaller than the measured steady-state value of 58, these are still high enough to enable correct strategic decision making regarding the need to evaluate the pharmacokinetics and activity profile of M2. As a general concept, this example illustrates the value of comprehensive understanding of the overall metabolic pathways of the parent drug and its metabolites when making these projections.

The very high M/P ratio for M2 (58-fold) (Table 7) may represent a limitation on the use of the static and PBPK models for predicting metabolite pharmacokinetics; i.e., the $\mathrm{M} / \mathrm{P}$ ratios that are in gross excess of unity may always be underpredicted. This is notable since eq. 1 is applied under the assumptions that parent and metabolite have stationary and linear pharmacokinetics, which is not the case with the current example. Nevertheless, predictions of steady-state $\mathrm{M} / \mathrm{P}$ ratios for $\mathrm{M} 2$ were 23 and 20 for static and PBPK models, respectively, which are still well in excess of unity. The input parameter sensitivity analysis revealed that the free fraction in plasma and metabolite formation and degradation intrinsic clearances were the most important parameters in determining the projected metabolite exposure values. This makes sense since these inputs are the ones that drive clearance, which in turn drives the overall exposure.

Future efforts are underway to expand the set of drugs and metabolites used to test these methods. In the present case, as well as in the previously described examples, the metabolites were formed and further cleared by P450 enzymes, and more examples will be useful to continue to test these methods. The most challenging cases are anticipated to be those wherein the metabolite is generated by less commonly encountered clearance mechanisms (i.e., other than P450), when parent and/or metabolite clearance occurs primarily by active transport (e.g., hepatic uptake, biliary secretion, renal secretion) and when the physicochemical properties of the metabolite are vastly different from the parent drug (e.g., weakly basic parent drug metabolized to weakly acidic metabolite, marked change in molecular weight and/or total polar surface area between parent and metabolite, etc.). In the case of TBPT and M2, the greatest difference is the change in the human plasma free fraction $(0.38-0.0025 ; 150$-fold difference) and it is this difference that most likely contributes to the high $\mathrm{M} / \mathrm{P}$ ratio, with $f_{\mathrm{u}}$ as a major contributor to systemic clearance. These future works could lead to refinement of the approach.

\section{Authorship Contributions}

Participated in research design: Obach, Sawant-Basak, Lin, Kimoto, Duvvuri, Nicholas.

Conducted experiments: Kimoto, Obach, Kadar.

Performed data analysis: Lin, Kimoto, Obach, Kadar, Duvvuri, SawantBasak.

Wrote or contributed to the writing of the manuscript: Obach, Sawant-Basak, Lin, Kimoto, Kadar, Tremaine, Duvvuri.

\section{References}

Brodney MA, Johnson DE, Sawant-Basak A, Coffman KJ, Drummond EM, Hudson EL Fisher KE, Noguchi H, Waizumi N, McDowell LL, et al. (2012) Identification of multiple $5-\mathrm{HT}_{4}$ partial agonist clinical candidates for the treatment of Alzheimer's disease. $J$ Med Chem 55:9240-9254.

Dalvie D, Obach RS, Kang P, Prakash C, Loi CM, Hurst S, Nedderman A, Goulet L, Smith E, $\mathrm{Bu} \mathrm{HZ}$, et al. (2009) Assessment of three human in vitro systems in the generation of major human excretory and circulating metabolites. Chem Res Toxicol 22:357-368

Houston JB (1981) Drug metabolite kinetics. Pharmacol Ther 15:521-552.

Isoherranen N, Hachad H, Yeung CK, and Levy RH (2009) Qualitative analysis of the role of metabolites in inhibitory drug-drug interactions: literature evaluation based on the metabolism and transport drug interaction database. Chem Res Toxicol 22:294-298.

Kimoto E, Li R, Scialis RJ, Lai Y, and Varma MV (2015) Hepatic disposition of gemfibrozil and its major metabolite gemfibrozil 1-O- $\beta$-glucuronide. Mol Pharm 12:3943-3952.

Loi CM, Smith DA, and Dalvie D (2013) Which metabolites circulate? Drug Metab Dispos 41: 933-951.

Lutz JD and Isoherranen N (2012) Prediction of relative in vivo metabolite exposure from in vitro data using two model drugs: dextromethorphan and omeprazole. Drug Metab Dispos 40: $159-168$.

Nguyen HQ, Callegari E, and Obach RS (2016a) The use of in vitro data and physiologically-based pharmacokinetic modeling to predict drug metabolite exposure: desipramine exposure in cytochrome P4502D6 extensive and poor metabolizers following administration of imipramine. Drug Metab Dispos 44:1569-1578.

Nguyen HQ, Kimoto E, Callegari E, and Obach RS (2016b) Mechanistic modeling to predict midazolam metabolite exposure from in vitro data. Drug Metab Dispos 44:781-791.

Nguyen HQ, Lin J, Kimoto E, Callegari E, Tse S, and Obach RS (2017) Prediction of losartanactive carboxylic acid metabolite exposure following losartan administration using static and physiologically based pharmacokinetic models. J Pharm Sci 106:2758-2770.

Nicholas T, Raunig D, Duvvuri S, Plotka A, Schwann E, Grimwood S, Park Y, Rowinski C, Rapp T, Bergeron M, et al. (2011) Pharmacokinetics, safety and tolerability of PF-04995274: a partial agonist being developed for the treatment of Alzheimer's disease. Alzheimers Dement 7S: S786-S787.

Pang KS and Rowland M (1977) Hepatic clearance of drugs. I. Theoretical considerations of a "well-stirred" model and a "parallel tube" model. Influence of hepatic blood flow, plasma and blood cell binding, and the hepatocellular enzymatic activity on hepatic drug clearance. J Pharmacokinet Biopharm 5:625-653.

Rothman RB, Baumann MH, Savage JE, Rauser L, McBride A, Hufeisen SJ, and Roth BL (2000) Evidence for possible involvement of 5- $\mathrm{HT}_{2 \mathrm{~B}}$ receptors in the cardiac valvulopathy associated with fenfluramine and other serotonergic medications. Circulation 102:2836-2841.

Sawant-Basak A, Coffman KJ, Walker GS, Ryder TF, Tseng E, Miller E, Lee C, Vanase-Frawley MA, Wong JW, Brodney MA, et al. (2013) Metabolism of a serotonin-4 receptor partial agonist 4-4-[4-tetrahydrofuran-3-yloxy)-benzo[d]isoxazol-3-yloxymethyl]-piperidin-1-ylmethyl-tetrahydropyran-4-ol (TBPT): identification of an unusual pharmacologically active cyclized oxazolidine metabolite in human. J Pharm Sci 102:3277-3293.

Shitara Y, Hirano M, Sato H, and Sugiyama Y (2004) Gemfibrozil and its glucuronide inhibit the organic anion transporting polypeptide 2 (OATP2/OATP1B1:SLC21A6)-mediated hepatic uptake and CYP2C8-mediated metabolism of cerivastatin: analysis of the mechanism of the clinically relevant drug-drug interaction between cerivastatin and gemfibrozil. J Pharmacol Exp Ther 311:228-236.

Smith DA and Obach RS (2006) Metabolites and safety: what are the concerns, and how should we address them? Chem Res Toxicol 19:1570-1579.

St-Pierre MV, Xu X, and Pang KS (1988) Primary, secondary, and tertiary metabolite kinetics. $J$ Pharmacokinet Biopharm 16:493-527.

Yu H, Balani SK, Chen W, Cui D, He L, Humphreys WG, Mao J, Lai GW, Lee AJ, Lim HK, et al (2015) Contribution of metabolites to P450 inhibition-based drug-drug interactions: scholarship from the Drug Metabolism Leadership Group of the Innovation and Quality Consortium Metabolite group. Drug Metab Dispos 43:620-630.

Yu H and Tweedie D (2013) A perspective on the contribution of metabolites to drug-drug interaction potential: the need to consider both circulating levels and inhibition potency. Drug Metab Dispos 41:536-540.

Address correspondence to: R. Scott Obach, Department of Pharmacokinetics, Dynamics, and Drug Metabolism, Pfizer Global Research and Development, Pfizer Inc., Groton, CT 06340. E-mail: r.scott.obach@pfizer.com 